\title{
An Experiential Model for Cultivating Cultural Humility and Embodying Antiracist Action in and Outside the Social Work Classroom
}

\author{
Kerri Fisher
}

\begin{abstract}
Social Workers in academia may enjoy seemingly endless discussions and debates on ever-evolving "diversity concepts" including privilege, oppression, microaggressions, and white supremacy culture, but students and would-be allies are often stymied, if not altogether lost by the enormity of overcoming injustice. The $7 E$ model for Cultural Humility and Antioppressive Practiceprovides specific and creative opportunities for personal and systemic change offeringfledgling antiracists both structure and freedom on their unique paths to activism and allyship in keeping with their own individual, intersectional identities and bio-psycho-social development. The seven experiences discussed in the model (exposure, engaging, examining, evaluating enacting, educating, and evolving) are defined and explained. Teaching tools are provided.
\end{abstract}

Keywords: Anti oppressive practice; White supremacy culture, cultural humility, DEI curriculum evaluation

As a black woman teaching in a predominantly white institution, I find that my students, colleagues, and community are often stymied by the enormity of overcoming racial injustice. Many, though not all, are willing learners, but their success as would-be change-makers is impeded by white supremacist norms in the academy including dichotomous thinking, perfectionism, and the right to comfort (Okun, 2010). If there is only "one right way" and if imperfect practitioners will be "canceled", emerging social workers are disincentivized from mining their intellectual and emotional depths for fear of what lies beneath polite professionalism.

Many approaches to comprehensive antiracist change suffer from either a lack of specificity or a lack of flexibility, leaving emerging professionals confused and ultimately disengaged from antiracism as a central, ongoing tenet of all of their professional endeavors. This is why a clear but adaptable model is needed that guides individuals through a set of experiences both personally and professionally, and which can begin and be reiterated throughout a social work curriculum in and outside the classroom.

The 7E Model for Cultural Humility and Antioppressive Practice, presented here for the first time, offers students and professionals a personal and professional pathway for deconstructing racism and reconstructing antiracism in thought, word, and deed. The model is informed by both critical race and intersectionality theories, and is also buoyed by the lifelong practices of cultural humility and counterintuitive solidarity. Each of these grounding concepts and practices is explained below.

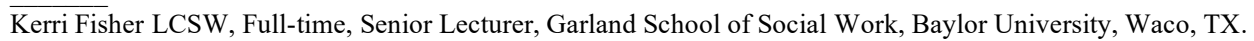




\section{Grounding Concepts \& Practices}

\section{Critical Race Theory}

Critical Race Theory is born of legal scholarship and informs social work practice with its acknowledgments that

1. Racism is a permanent and embedded

2. Race is socially constructed

3. Whiteness is a commodity that can be bartered for goods, services, and opportunities

4. White individuals and institutions can choose to be or appear to be anti-racist when it benefits the white stakeholders (interest convergence)

5. Intersectional identities affect racism's overall impact

6. Storytelling and counter-storytelling are key to understanding race and racism accurately

7. Ahistoricism and colorblind classical liberalism must be identified and critiqued

(Daftary, 2018, p. 442)

In particular, the 7E Model encourages critical self-reflection around the permanent and embedded racism in individuals \& institutions, engagement, and emphasis on counternarratives from Black, Indigenous, Latino(a)(x), Asian, biracial, multiracial, and other nonwhite groups, and levying the commodity of whiteness (or any other privileged identity) for the benefit of antiracist initiatives. I hesitate to use the recently popularized BIPOC label for fear that it might have the unintended effect of erasure of my Latino(a)(x) and Asian colleagues and collaborators in the fight for racial justice. Lusk (2017) addresses the need for a critical lens in social work supervision and leadership in order for cultural competence to be enacted effectively.

\section{Intersectionality}

Though intersectionality is a recognized component of critical race theory, the work of Dr. Kimberlé Crenshaw deserves its own explanation as a fundamental element of the 7E model. Many social work educators have articulated the need for intersectionality in any cultural competence instruction (Robinson et al., 2016; Ross, 2010). Crenshaw, along with other legal scholars, recognized the many ways that marginalizations in multiple identities such as race and gender overlap and in so doing create barriers in a person's life that might otherwise be avoided. For example, in the Degaffernreid case famously analyzed by Crenshaw (1989), five black women who filed an employment discrimination case against General Motors, were told that they could not have been discriminated against because there were both women and black people employed at the company. The ruling judge failed to take into consideration that it was, in truth, the overlapping of their identities - blackness plus femaleness, that created the discrimination and thus the block in their professional progress. 
Although no two people nor marginalizations are exactly the same, it seems that using anti-oppressive work in one area of learning can often be adjusted and appropriately generalizable to other areas of learning. Students are done a disservice when educators seek to combat inequity for one or two groups due to personal connection or mounting public pressure. True justice in education comes from always asking the question, how can we create the least restrictive environments for all students? Those who desire to be "problack" educators must remember that some black students are also gay students. Those institutions desiring to be queer-friendly campuses have to recognize that some of their queer students are also religious minorities. For those communities priding themselves on being multiculturally inclusive, it will be of utmost importance to listen to the voices of women from all those cultures rather than histories, traditions, and desires, offered exclusively through the male lens and the male gaze.

\section{Cultural Humility}

Cultural Humility is a term coined by physicians Dr. Melanie Tervalon and Dr. Jann Murray-Garcia (1998), who came to understand that the nurses they were training not only had preconceived race-based notions about patients but also that some of their notions seemed, at times, to be academically sanctioned misinformation. They came to believe that the formerly hailed cultural competence model might have the unintended consequence of giving health professionals a misguided sense of expertise just because they read a book or heard a lecture about working with patients from certain racial or ethnic backgrounds. Instead, the doctors suggested, a better approach would be one of cultural humility, the tenets of which they identified as "a commitment to lifelong learning \& critical selfreflection, challenging power imbalances, and holding institutions accountable for and to the communities of color which they purport to serve" (Tervalon \& Murray-Garcia, 1998, p. 118). Ortega and Faller (2011) and Gottlieb (2020) have expanded upon Tervalon and Murray-Garcia's concept of cultural humility as a strong philosophical fit for the social work profession in particular.

Many have written about the pros and cons of both cultural competence and cultural humility in the field of social work. Critiques of cultural competence include ambiguous and inconsistent definitions held by practitioners, a focus on mastery (static endpoint) rather than accountability (ongoing assessment; Fisher-Borne et al., 2015), a tendency toward an imprecise conflation of race and culture (Jani et al., 2016), and a diversion from a central emphasis on the impact power and oppression (Abrams, 2009).

Cultural Humility has also been critiqued, especially when lifelong learning has been overvalued at the expense of critical self-reflection, addressing power, and institutional accountability. Though social workers should be open to learning about the impact of clients' intersectional identities, more onus should not be placed on marginalized individuals/groups to be the teacher of their experiences for counselors, case managers, or other social workers in the community when ample research, literature, and art exists for those interested in educating themselves.

Because both cultural competence and cultural humility have been repeatedly misunderstood and misapplied, it is helpful that the latest update to the NASW Code of 
Ethics (National Association of Social Work, 2021) now elevates Tervalon and MurrayGarcia's cultural humility orientation, in the ethical standards section reminding social workers of our ethical obligations not only to "obtain knowledge" (1.05d) through "critical self-reflection" (1.05c) but also to "demonstrate understanding" through "holding institutions accountable" $(1.05, \mathrm{~d})$ and "taking action against oppression, racism, discrimination, and inequities $(1.05, \mathrm{~b})$

\section{Counterintuitive Solidarity}

Finally, at the center of any good cultural humility is counterintuitive solidarity, a practice named and described by Dr. Drew Hart. Hart (2016) suggests that individuals with political and social power have never tended to easily and accurately intuit the plight of the disenfranchised. If Critical Race Theory affirms for learners that racism is a permanently embedded part of culture, counterintuitive solidarity reminds learners that it took many complicit, silent, and/or apathetic white individuals choosing to believe or hide behind the religious, sociological, and supposedly scientific rationales for its continued existence.

Rather than assigning villainy or idiocy to those who came before, educators should instead encourage students to assume such patterns of behavior continue among the socially, financially, politically, and historically, privileged and powerful. Whose voice is getting drowned out today? What are they saying? Who benefits from not listening/knowing/believing them? Counterintuitive solidarity asks antiracist allies and advocates to remember the sins of the past and assume that nothing will or can change without listening, trusting, and following the collective voice of those who are oppressed today.

Figure 1. 7E Model for Cultural Humility and Antioppressive Leadership

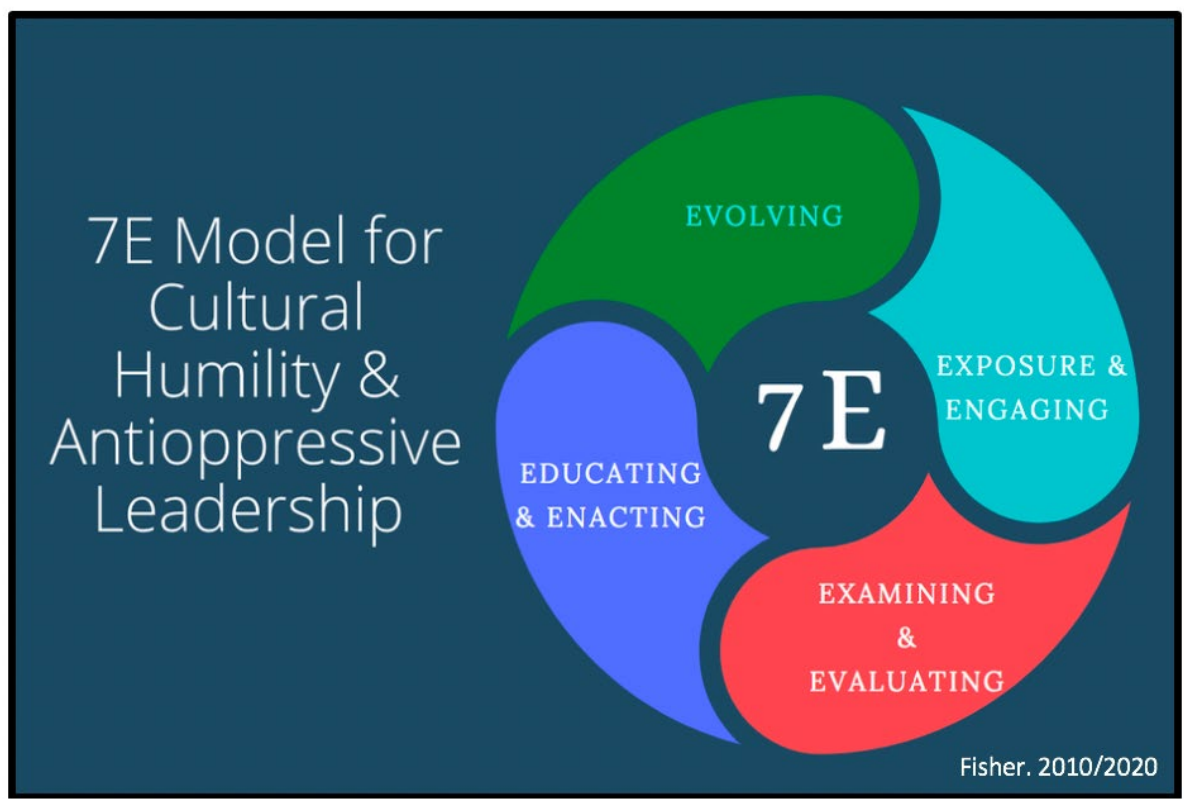




\section{Introduction \& Structure}

The $7 E$ model for Cultural Humility and Antioppressive Action depicted in figure 1 is a culmination of 15 years of experience as a social work practitioner, field director, and educator. The model moves from intrapersonal work connected to the "lifelong learning and critical self-reflection" tenet of cultural humility and moves increasingly into interpersonal and institutional level action in keeping with the tenets of "challenging power imbalances" and "holding institutions accountable" (Tervalon \& Murray-Garcia, 1998, p. 118).

Step-based models can easily become cemented in individual minds and collective consciousness as linear, hierarchical, and static - a very western, "objective" manner of engaging information, when in truth, much of life and learning tends to be interconnected, dynamic, and cyclical (if any structurally reliable pattern exists at all). For that reason, the $7 \mathrm{E}$ model uses the word "experience" rather than "step" to describe states of awareness and action. Experiences sometimes happen in the order described, and at other times they happen concurrently or partially concurrently. Most educators can attest to the variety of learning trajectories in the lives of students, colleagues, and loved ones who have joined the path of peace-making resistance. Below each of the seven experiences is described, for ushering students through exposure, engaging, examining, evaluating, enacting, educating and evolving.

\section{"Encounter" Experiences: Exposure \& Engaging}

Encounter experiences are any experiences (whether incidental or intentional) in which an individual has occasion to observe, consume, or participate in an activity that is foreign to their own intersectional identities and experiences. An easy way to identify such experiences is to consider what students are reading, watching, listening to and/or attending. Many students have had limited academic encounters with the offerings of nonwhite scholars, artists, and citizens, a phenomenon known as invisibility (Pharr, 1988) or erasure. When students have been exposed to such offerings the content is often singular and/or distorted by the white gaze (Paris \& Alim, 2014), for example, when every case study offered features straight, young, black men struggling with drug misuse or every "Hispanic Heritage" month is celebrated by a cursory "Taco Tuesday" mixer.

This is why an intersectional approach is so important in teaching and offering antiracist encounter experiences. Students who identify as Black, Indigenous, Latino(a)(x), Asian, biracial, multiracial, or otherwise non-white do not benefit from repeatedly being cast as "other" and, in fact, are in danger of experiencing vicarious trauma when every class reading, lecture, or activity reminds and reifies the notion that whiteness is the default experience against which all other experiences are compared (Cunningham, 2004; Pharr, 1988). Using an intersectional approach offers the opportunity for students to toggle back and forth between reading/watching/listening/attending from the perspective of privilege and marginalization, as it is unlikely that many students in a given classroom inhabit all marginalized identities. Additionally, antiracist education is not truly antiracist if only one version of, for example, indigenous identity is offered for exploration. 
Four tools that can help educators and students to create and/or mine student encounter experiences in and outside of the classroom are the Course Content Check (Table 1), Social Location Inventory (Table 2), Relational Inventory (Table 3), and Content Intake Log (Table 4). These tools can be found in Tables 1-4 of this paper but descriptions and tips for use are offered below.

\section{Encounter Tool Tips}

1. It is important that cultivated encounter experiences feature art, literature, scholarship, and activities that are created by, and not simply about individuals from a marginalized group. A white writer who is an American citizen by birth is likely to have a very different take on a Mexican immigration narrative than a Mexican or Mexican-American writer.

2. It is important that would-be antiracists are encouraged to resist the urge to compare "our best with their worst" (Mclaren, 2004, p. 149). If an instructor assigns only one article about Muslim-identifying black men, she should consider and/or discuss with students the potentially deleterious effects of such a choice.

3. It is important to remember and remind students that cultural events/activities should be attended only by invitation so as not to exploit a marginalized ingroup experience for the benefit of the dominant-group need.

\section{Encounter Tool Descriptions}

The Course Content Check (Table 1) is a tool that helps instructors make sure that their in-class offerings have been intentionally selected for intersectionally diverse course content and that this intentionality is not left up to students to notice or intuit. It is important to highlight Black and Brown voices and to offer an explanation wherever certain perspectives have been left out.

Both the Intersectional Social Location Inventory (Table 2) and the Relational Inventory (Table 3) are tools that can be used inside or outside of class for students to acknowledge and engage their own intersectional identities/lived experiences, which then inform where there might be gaps in natural learning opportunities and point to places where more exposure and engagement are needed. These tools also encourage examination and could therefore be considered Reflective Experience tools.

The most immediate exposure/engagement tool to use as an encounter experience assessment and intervention is the Content Intake Log (Table 4). Taking inventory of reading, watching, listening, and participation habits allow students to make goals for change. For example, if a student finds that they engaged no content offered by Black creators in the last year, and if they are being taught that racism is permanent and embedded and must be combatted with counternarratives, then perhaps the student will make a goal for increased exposure to Black created content in the year to come. 
Table 1a. Course Content Check

Encounter Experiences Tool 1:

Course Content Check (Intersectional Decentering of Dominant Groups)

1. "By" Not "About" Content Check: How many content elements (readings, videos, guest speakers, etc.) are written/provided $\boldsymbol{b y}$ (as opposed to about) non-dominant status individuals/groups?

2. "About Content" Check: How many content elements (readings, videos, guest speakers, etc.) are about (though not necessarily by) non-dominant status individuals/groups?

3. Bias Check: When non-dominant groups are featured, how frequently is the appearance evidently one of pity, shame, trauma, dysfunction, or otherwise stereotypical representation?

4. Strengths Check: When non-dominant groups are featured, how frequently is the appearance evidently one of strength, dignity, beauty, competence, leadership, etc.?

5. Person First Check: When non-dominant groups are featured, are they exclusively used to speak on issues related to their marginalized identity? (Example: I invite my one Asian-American colleague to speak in my class each year about Asian identity and not about his research area which is actually aging.)

6. Visibility Check: What can I do to make unseen contributions seen? (Example, showing photos /video clips of Black writers/researchers during in-class lecture lest students presume the writer/researcher/artists from their course outlines are all or mostly dominant group contributors.)

7. Presumed Center/ Re-traumatization Check: Have I given options and/or trigger warnings where to read, watch, listen-to, or engage a piece of assigned content could be retraumatizing for marginalized individuals, or have I (inappropriately) presumed all of my students will be in the dominant group? (Example: If I assign a video-clip that shows a person with a disability/disorder getting cruelly taunted, whether or not I am aware of a student with that particular disability/disorder I might need to write in a trigger warning, and I might choose to offer alternative content in the instructions for individuals who share an identity with the person being bullied in the video. It is best if this is written into the instructions from the outset, and not merely granted as an exception for a student who voices discomfort.) *

8. Thomas Theorem Check: What is perceived as real is real in its consequences. Therefore, how must I clearly articulate/verbalize my rationale/reasoning for any controversial/missing material? (Example: Saying to students "This semester 8 out of 10 of our guest speakers were straight, white, women. I want to let you know that I worked to get a more diverse panel to better represent our community of practitioners, but several BIPOC who I invited were unexpectedly unable to attend. Additionally, I am new in town and unaware of any queer practitioners at this time, but it is my priority to find out for my next round of guest speakers.")

* This is not to indicate that emerging practitioners should never be asked to engage tough and even potentially wounding material to prepare them for work in the field, but rather to be cognizant of the age/stage and mental health of the learners in any given classroom setting. 


\begin{tabular}{|l|l|l|l|}
\hline \multicolumn{1}{|c|}{ Table 1b. Course Content Check (continued)* } \\
\hline Women & $\begin{array}{c}\text { Appearance in } \\
\text { Course Content } \\
\text { (Unit/Week) }\end{array}$ & $\begin{array}{c}\text { Nature of } \\
\text { Appearance } \\
\text { (By? About? +, -) }\end{array}$ & $\begin{array}{c}\text { Relevant Notes/ } \\
\text { Exclusions, etc. }\end{array}$ \\
\hline Black people & & & \\
\hline Latino(a)(x) people & & & \\
\hline Asian-American people & & & \\
\hline Indigenous people & & & \\
\hline $\begin{array}{l}\text { International people and/or } \\
\text { people who have immigrated }\end{array}$ & & & \\
\hline People with/from low SES & & & \\
\hline LGBT/queer people & & & \\
\hline $\begin{array}{l}\text { People with disability/ } \\
\text { disorder(s) }\end{array}$ & & & \\
\hline Older adults & & & \\
\hline $\begin{array}{l}\text { People who are religious } \\
\text { minorities }\end{array}$ & & & \\
\hline Future planning: & & & \\
\hline
\end{tabular}

*Note: Table filled out using course syllabus 
Table 2. Intersectional Social Location Inventory Encounter Experiences Tool 2: Intersectional Social Location Inventory

\begin{tabular}{|c|c|c|}
\hline $\begin{array}{l}\text { Race/Ethnicity } \\
\text { HP: } \\
\text { HO: }\end{array}$ & $\begin{array}{l}\text { Socioeconomic } \\
\text { Status/Education } \\
\text { HP: } \\
\text { HO: }\end{array}$ & $\begin{array}{l}\text { HP: } \\
\text { HO: }\end{array}$ \\
\hline $\begin{array}{l}\text { Ability } \\
\text { HP: } \\
\text { HO: }\end{array}$ & $\begin{array}{l}\text { Gender-Identity } \\
\text { HP: } \\
\text { HO: }\end{array}$ & $\begin{array}{l}\text { Nationality/Status } \\
\text { HP: } \\
\text { HO: }\end{array}$ \\
\hline $\begin{array}{ll} & \text { Orientation } \\
\text { HP: } & \\
\text { HO: } & \end{array}$ & $\begin{array}{l} \\
\text { HP: } \\
\text { HO: }\end{array}$ & $\begin{array}{l}\text { HP: } \\
\text { HO: }\end{array}$ \\
\hline
\end{tabular}

$\mathrm{HP}=$ Historically Privileged $\mathrm{HO}=$ Historically Oppressed

Questions for Reflection

1. Fill in the historically privileged and historically oppressed groups for the country where you live/serve/practice.

2. Make note of the number of squares where you fall into the HP category.

3. What do you notice?

4. How do you feel?

5. How is this information helpful?

6. How is it challenging?

7. Where might you have gaps in your learning and/or the need to practice counterintuitive solidarity?
Table 3. Relational Inventory

Encounter Experiences Tool 3: Relational Inventory

1. How many people of color (or other marginalized group) have I had a meaningful conversation within the last week/month? Were these conversations reciprocally meaningful? What evidence do I have for that? (Consider context, power differentials, etc.)

2. How many people of color (or other marginalized group) live on my street or in my neighborhood/apartment complex?

3. How many people of color (or other marginalized group) have I invited to my home?

4. How many people of color (or other marginalized group) do I work/attend school with?

5. If I am a part of a faith community, how many people of color (or other marginalized group) are in my faith community?

6. If I am a part of civic or recreational groups, how many people of color (or other marginalized group) are in these groups with me?

7. What do I want for my life and the life of my loved ones with regard to relational intimacy/community with people who are different from me/us?

8. What will I commit to do doing in the next week/month/year of my life in this area (without being inappropriate, self-involved, exploitative, etc.)? 
Table 4. Encounter Experiences Tool 4: Intake Log

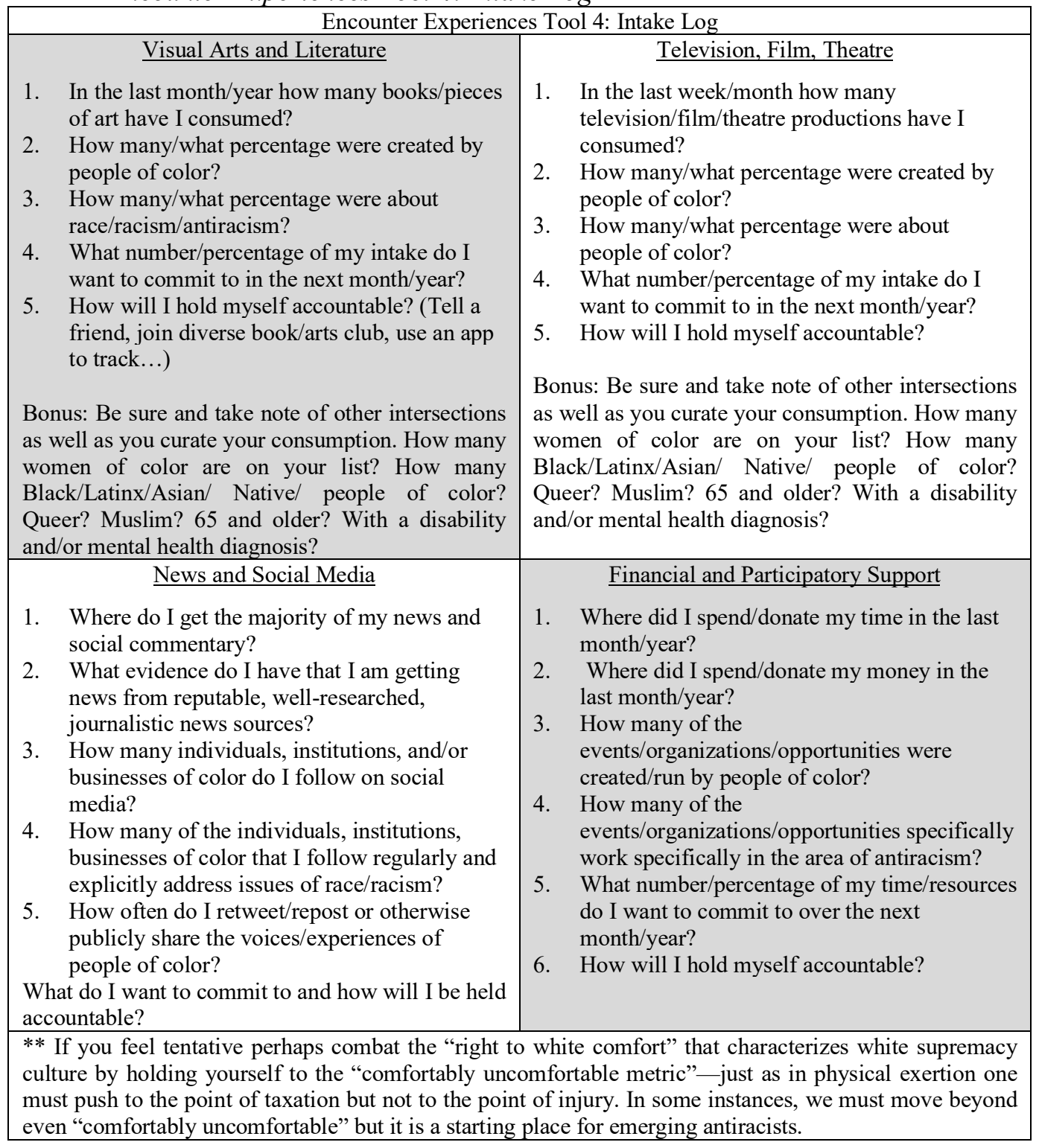

\section{Reflective Experiences: Examining \& Evaluating}

Reflective Experiences can happen before, during, or after Encounter Experiences and are characterized by examining thoughts, feelings, and actions in anticipation of, or in response to, engaging with new people, content, and/or experiences. Initially, "examination" is meant to be practiced as a non-judgmental self-observation, simply noticing changes in the three b's "body" (ex: sweat, tears), "brain" (ex: judgments, defense mechanisms) and "behavior" (ex: yelling, leaving). 
Racism has so thoroughly and appropriately been vilified (if only theoretically) in polite culture, that students often have a difficult time admitting to racism in thought, word, or deed. This is why teaching specific ways to self-examine is key to successful reflective work. Once students have been able to notice body, brain, and behavioral reactions in Reflective Experience Tool 1: Three B Examination Process (Table 5), they can evaluate whether any of their initial responses are worth keeping or worth letting go. If the systems and cultures socializing students and educators are inundated with "ist" (rhymes with mist) and "ic" (rhymes with sick) ways of being it only makes sense that some "ist" (racist, classist, sexist, heterosexist, ableist, ageist) and "ic" (Xenophobic, Islamophobic, transphobic) notions and behaviors have become a part of everyone. It is helpful to remind students of the maxim "we are not responsible for our first thought, but rather for our second thought and our first action."

\section{Table 5. Reflective Experience Tool 1: Three B Examination Process}

\section{Reflective Tool 1: Three B Examination Practice}

Try asking the following reflective questions after one or more of the following encounter experiences:

- A visit to a new restaurant that is ethnically/culturally different than your own

- A conversation with a friend from a marginalized identity of which you are not a part or which you share but have been asleep to/divorced from in some way

- A book, song, podcast, show, film, or any art by (or potentially about) a person/group a marginalized identity of which you are not a part or which you share but have been asleep to/divorced from in some way

\begin{tabular}{|c|c|c|}
\hline $\begin{array}{l}\text { Brain } \\
\text { - What are my automatic thoughts? } \\
\text { - What are my judgments? } \\
\text { - What am I } \\
\text { avoiding/resisting/refusing? } \\
\text { What are any alternative/opposing } \\
\text { narratives I am coming up with in } \\
\text { contrast with what I am being } \\
\text { asked to believe/hear/experience? }\end{array}$ & $\begin{array}{l}\text { Body } \\
\text { - Is my heart racing? } \\
\text { - Am I flushed/hot? } \\
\text { - Sweaty? } \\
\text { - Crying? } \\
\text { - Clinched? } \\
\text { - Numb? } \\
\text { - Do I have excess energy? } \\
\text { - Am I exhausted? }\end{array}$ & $\begin{array}{l}\text { Behaviors } \\
\text { - Am I leaving/quitting or } \\
\text { trying to leave/quit? } \\
\text { - Am I zoning out? } \\
\text { (Dissociating) } \\
\text { - Raising my voice? } \\
\text { - Refusing my voice? Fighting? }\end{array}$ \\
\hline
\end{tabular}

Because it is challenging for emerging antiracists to evaluate whether an initial response may have been racist, it is important to provide specific definitions and examples of racism in action that can be referred back to for evaluation purposes. Depending on the course and instructor, various definitional tools might be selected as a racial litmus test. Suggested materials include Suzanne Pharr's (1988) Mechanisms of Oppressions updated by Hutchison (2016), Sue et al.'s (2011) Microaggressions and Tenets of White Supremacy Culture as named by Okun (2010) and Saad (2020).

Because students sometimes struggle with real-time analysis the Reflective Tool 2: Retrospective Engagement Journal (Table 6) offers practice examining and evaluating scenes from their individual racial socialization at an earlier stage in their growth and development. 
Table 6. Reflective Tool 2: Retrospective Engagement Journal

Reflective Experiences Tool 2: Retrospective Engagement Journals (Race)

1. My first positive/proud awareness of race/ethnicity* was when $?$

2. My first negative/shame inducing awareness of race/ethnicity was when ?

3. What was I told explicitly about my race/ethnicity? (Think of direct teaching/comments which came from family, friends/neighbors, school/educators, faith community, media, etc.)

4. What was I told explicitly about people who were different from me in terms of race/ethnicity? (Think of direct teaching/comments which came from family, friends/neighbors, school/educators, faith community, media, etc.)

5. What did I see modeled for me in terms of belief/treatment of people who were my race/ethnicity?

6. What did I see modeled for me in terms of belief/treatment of people who were not my race/ethnicity?

*This can be done for any intersectional identity including: gender, socioeconomic status, orientation, gender identity, religion, nationality, ability, age.

\section{Interventive Experiences: Enacting \& Educating}

While Encounter and Reflective experiences primarily help students develop the "lifelong learning" and "critical self -reflection" tenets of cultural humility, interventive experiences move into the more actively antiracist tenets of challenging power imbalances and holding institutions accountable. Educating \& enacting change means practicing microresistance in interpersonal relationships and macroresistance strategies when the systems and institutions of which we are a part are guilty of white supremacy in policies, procedures, or practices.

\section{Microresistance Strategies (Table 7)}

The term microaggression has come under some academic scrutiny, however microresistance strategies are labeled as such not because they are small resistances to inconsequential racism, but rather because they are resistances that take place repeatedly at the interpersonal rather than the systemic level. The four interpersonal, microresistance strategies suggested are Check-In, Find Out More, Open The Front Door (Ganote et al., n.d.) and Self-Care. 
Table 7. Microresistance Strategies for Potential Allies

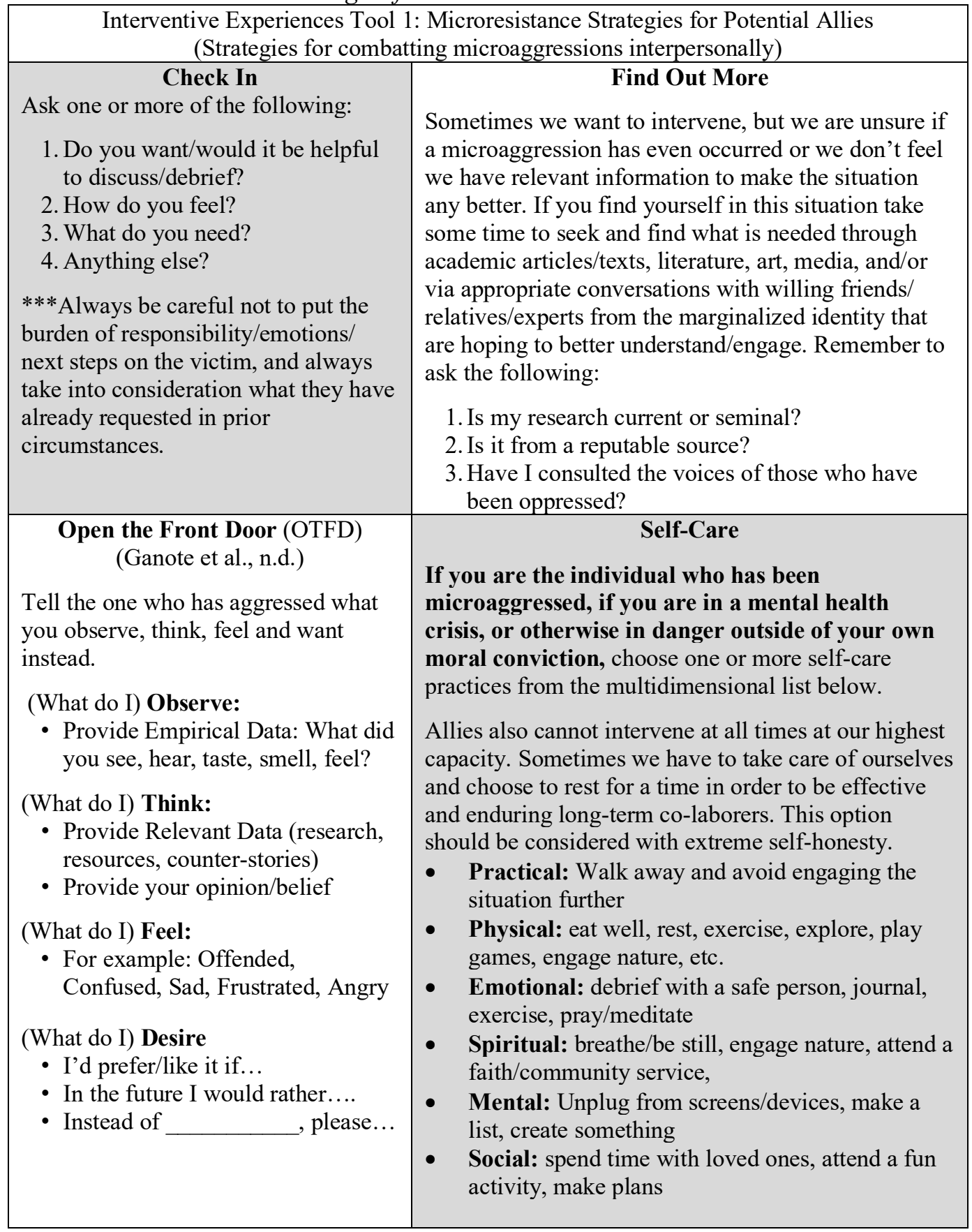


Check-In. Encouraging the practice of checking in with those who are the victims (or potential victims) of interpersonal degradations ensures that emerging anti-racists do not inadvertently make a bold and potentially harmful decision without consulting those who will be most impacted by the resulting consequences of such an action.

Find Out More. Sometimes students are unsure whether or not an interpersonal indignity has even occurred. For this reason, Find Out More encourages them to research the interpersonal behavior in question without putting the responsibility on a Black, Indigenous, Latina(o)(x), Asian, Biracial, Multiracial or otherwise non-white individuals to do the bulk of the emotional labor unnecessarily.

Open the Front Door (OTFD). Ganote et al. (n.d.) have provided a great step by step process for intervening when an interpersonal indignity occurs. The suggested steps are "O", or "observe", which consists of naming the observed microaggressive indignity, "T \& F", or "Thoughts and Feelings, which means "reporting personal thoughts and feelings about the problematic behavior, and finally " $\mathrm{D}$ ", or "desire", which means expressing a clear directive for different behavior in the future. A sample OTFD communication might look like this:

- Observe: I noticed that you repeatedly interrupt and talk over students of color in the classroom.

- Thoughts: This is not rare. It actually happens a lot in higher education settings even unconsciously.

- Feelings: It makes me concerned though, about your future in social work if you are unwilling to hear out people who are different than you.

- Desire: The eye-rolling has to stop and I would like you to try and notice when, how, and over whom you are speaking in my class.

Self-Care. Finally, though the 7E model is predominantly a tool for allies, it is important to acknowledge that self-care and opting out of the conversation are important options for students who are experiencing racial trauma and vicarious trauma in and outside of their academic institutions.

\section{Macroresistance Strategies (Table 8)}

Macroresistance strategies are named as such not because they are more important than interpersonal (micro) strategies but because they are ways of engaging at the systemic level of change. The four categories of macroresistance strategies are interrogate, disrupt, advocate and create.

- Interrogate. These are strategies that center around asking questions and gathering data which will ultimately get conversations and collaborations started in an agency, institution, and/or community setting.

- Disrupt. These strategies focus on interrupting false information, accusations, and suppositions that result in ongoing actively and subtly racist policies, procedures and practices. 
- Advocate. This macroresistance category encourages taking a stand through opportunities like voting, raising awareness, financial contributions, and levying privilege.

- Create. Finally, students are asked to consider designing and implementing curriculum, groups, programming, art, and other generative experiences in the systems where they work and serve.

Reminders for each of these resistance categories are provided in the interventive experiences tools provided in the appendices. These can be used in the classroom by providing students with case studies and having them choose two or three of the resistance strategies they might employ, or in field education as examples of evidence that can be cited on learning contracts and evaluation tools.

\section{Table 8. Macroresistance Strategies}

\begin{tabular}{|l|l|}
\hline \multicolumn{2}{|c|}{ Interventive Experiences Tool 2: Macroresistance Strategies for Potential Allies } \\
(Strategies for changing systems and processes)
\end{tabular}

\section{Maintenance Experience: Evolving}

Any model must have a maintenance mechanism and any antiracist model must honor the requirement to evolve because systems will always continue to find ways to evade and 
pervert justice. Truly humble and anti-racist activists must be agile enough to take in new data, learn fresh terminology, and employ emergent strategies.

It is important for educators to model and narrate the ways that they are ever-evolving in their own antiracist work. Ways to demonstrate evolution include regularly updating class content, noting language changes (especially those related to marginalized identities) and encouraging students to share their ongoing expertise through in-class conversations, discussion boards, and extracurricular leadership. Students and educators should also remember that even those evolving in one area of antioppressive work such as race might find themselves in the encounter stage of engaging with another intersectional identity such as religion, spirituality, and worldview (RSW).

\section{Conclusion}

Social Work educators must simultaneously provide students a path to deconstruct selfsatisfied, self-inflated, self-congratulation, and to reject the unhelpful illusions of progressive purity and perfect advocacy which keep would-be interrupters, resisters, and creators from interrupting, resisting and creating for fear their offerings will never be good or right enough. It is the role of the educator to see, hear, and raise up whole people who own, articulate, and wield the mixed bag of privileges and marginalizations their identities have provided, and offer places at the table of justice for storytellers and statisticians, fledglings and sages alike. The $7 E$ model for Cultural Humility and Antioppressive Practices offers an organized, approachable process for lifelong commitment to strategic and spontaneous allyship through each experience life and education have to offer.

\section{References}

Abrams, M. (2009). Critical race theory and the cultural competence dilemma in social work education. Journal of Social Work Education, 45(2), 245-261. https://doi.org/10.5175/JSWE.2009.200700109

Crenshaw, K. W. (1989). "Demarginalizing the Intersection of race and sex: A Black feminist critique of antidiscrimination doctrine, feminist theory and antiracist politics. University of Chicago Legal Forum, 1989(1), 139-167.

http://chicagounbound.uchicago.edu/uclf/vol1989/iss1/8

Cunningham, M. (2004). Teaching social workers about trauma: Reducing the risks of vicarious traumatization in the classroom. Journal of Social Work Education, 40(2), 305317. https://doi.org/10.1080/10437797.2004.10778495

Daftary, A. M. H. (2018). Critical race theory: An effective framework for social work research. Journal of Ethnic \& Cultural Diversity in Social Work, 29(9), 439-454. https://doi.org/10.1080/15313204.2018.1534223

Fisher-Borne, M., Caine, J. M., \& Martin, S. L. (2015). From mastery to accountability: cultural humility as an alternative to cultural competence. Social Work Education, 34(2), 165-181. https://doi.org/10.1080/02615479.2014.977244 
Ganote, C., Souza, T., \& Cheung, F. (n.d.). Microresistance and ally development: Powerful antidotes to microaggressions. https://www.unomaha.edu/facultysupport/teaching-excellence/microaggressions-handout.pdf

Gottlieb, M. (2020). The case for a cultural humility framework in social work practice. Journal of Ethnic \& Cultural Diversity in Social Work, online first, 1-19. https://doi.org/10.1080/15313204.2020.1753615

Hart, D. G. I. (2016). Trouble I've seen: Changing the way the church views racism. Herald Press.

Hutchison, E. (2016). Dimensions of human behavior: Person and environment (6th ed.). Sage Publications.

Jani, O., Osteen, P., \& Shipe, S. (2016). Cultural competence and social work education: Moving toward assessment of practice behaviors. Journal of Social Work Education, 52(3), 311-324. https://doi.org/10.1080/10437797.2016.1174634

Lusk, T. (2017). Critical cultural competence in social work supervision. Human Service Organizations, Management, Leadership \& Governance, 41(5), 464-476. https://doi.org/10.1080/23303131.2017.1313801

Mclaren, B. (2004). A Generous Orthodoxy. Zondervan.

National Association of Social Work [NASW]. (2015). Standards and indicators for competence in social work practice. NASW. https://www.socialworkers.org/LinkClick.aspx?fileticket=7dVckZAYUmk\%3D\&por $\underline{\text { talid }=0}$

Okun, T. (2010). The emperor has no clothes: Teaching about race and racism to people who don 't want to know. IAP Information Gap Publishing.

Ortega, R. M., \& Faller, K. C. (2011). Training child welfare workers from an intersectional cultural humility perspective. A paradigm shift. Child Welfare, 90(5), 27-49. https://doi.org/10.1037/e516652013-008

Paris, D., \& Alim, S. (2014). Pedagogy beyond the white gaze. The Blog of Harvard Education Publishing. https://www.hepg.org/blog/pedagogy-beyond-the-white-gaze

Pharr, S. (1988). Homophobia: A weapon of sexism. Chardon Press.

Robinson, C. (2016). Teaching note-teaching intersectionality: Transforming cultural competence content in social work education. Journal of Social Work Education, 52(4), 509-517. https://doi.org/10.1080/10437797.2016.1198297

Ross, L. (2010). Notes from the field: Learning cultural humility through critical incidents and central challenges in community-based participatory research. Journal of Community Practice, 18, 315-335. https://doi.org/10.1080/10705422.2010.490161

Saad, L. (2020). Me and white supremacy. Sourcebooks.

Sue, D. W., Capodilupo, C. M., Torino, G. C., Bucceri, J. M., Holder, A. M. B., Nadal, K. L., \& Esquilin, M. (2007). Racial microaggressions in everyday life: Implications 
for clinical practice. American Psychologist, 62(4), 271-286.

https://doi.org/10.1037/0003-066x.62.4.271

Sue, D. W., Rasheed, M. N., \& Rasheed, J. M. (2016). Multicultural social work practice: A competency-based approach to diversity and social justice (2nd ed.). Jossey-Bass.

Tervalon, M., \& Murray-García, J. (1998). Cultural humility versus cultural competence: A critical distinction in defining physician training outcomes in multicultural education. Journal of Health Care for the Poor and Underserved, 9(2), 117-125. https://doi.org/10.1353/hpu.2010.0233

Author note: Address correspondence to Kerri Fisher, Garland School of Social Work Baylor University, Waco, TX, 76798. Email: kerri_fisher@baylor.edu 